\title{
Subgroup dairy products consumption on the risk of stroke and CHD: A systematic review and meta-analysis
}

\author{
Fatemeh Gholami ${ }^{1}$, Malihe Khoramdad ${ }^{1 *}$, Ebrahim Shakiba², Yousef Alimohamadi ${ }^{3,4}$, Jabbar Shafiei ${ }^{5}$, Alireza Firouzi $^{6}$
}

\begin{abstract}
Background: There is no global consensus about the relationship between dairy consumption and cardiovascular diseases (CVD). This study aimed at integrating the results of several studies to predict the dairy effects on CVD, e.g. stroke and CHD.

Methods: In the present study, some major databases such as Scopus, Science Direct, and PubMed were searched up to September 2014. All prospective cohort studies dealing with dairy products consumption and CVD were surveyed regardless of their publication date or language. This reference population includes all individuals without any delimitation with regard to age, gender, or race. The quality of the study was evaluated using STROBE Checklist. Study selection and data extraction were done by 2 independent researchers separately. The indices in this study were RR and HR. The random model was used to combine the results.

Results: Out of 6234 articles, 11 were included in the meta-analysis. No relationship was found between stroke and consumption of milk, cream, and butter, and the results are as follow: $\mathrm{RR}=0.91$ (95\%CI: $0.81-1.01)$ for milk, $\mathrm{RR}=0.97$ (95\%CI: $0.88-1.06)$ for cream, and $\mathrm{RR}=0.95$ (95\%CI: $0.85-1.07)$ for butter. However, cheese was found to decrease stroke risk: $\mathrm{RR}=0.93$ (95\%CI: $0.88-0.99)$.

The relationship of CHD with consumption of milk, cheese, cream, and butter are as follows, respectively: RR $=1.05$ (95\% CI: 0.96 1.15), $\mathrm{RR}=0.90$ (95\%CI: 0.81-1.01), $\mathrm{RR}=0.96$ (95\% CI: 0.87-1.06), and $\mathrm{RR}=0.99$ (95\% CI: 0.89-1.11). In other words, no relationship existed between dairy products and CHD.

Conclusion: No relationship was found between consumption of various dairy products and CHD or stroke, except for cheese that decreased stroke risk by $7 \%$. Considering the small number of studies, the result of the present study is not generalizable and more
\end{abstract} studies need to be conducted.

Keywords: Dairy Products, CHD, Stroke, Cardiovascular Disease, Meta-analysis

Copyright@ Iran University of Medical Sciences

Cite this article as: Gholami F, Khoramdad M, Shakiba E, Alimohamadi Y, Shafiei J, Firouzi A. Subgroup dairy products consumption on the risk of stroke and CHD: a systematic review and meta-analysis. Med J Islam Repub Iran. 2017 (27 Mar); 31:25. https://doi.org/10.18869/mjiri.31.25

\section{Introduction}

Cardiovascular diseases (CVD) are one of the 10 most important causes of death worldwide. According to World Health Organization (WHO) statistics, 17.5 million people died of CVD around the world in 2012, making up 31\% of the total mortality rate worldwide. Of these death cases, 7.4 million were due to CHD (coronary heart disease) and 6.7 million were caused by stroke. It is predicted that the mortality from CVD will increase to 23.6 million cases in 2030 (1).

Dairy products are rich in minerals (calcium, potassium,

\footnotetext{
Corresponding author: Malihe Khoramdad, m.khoramdad2016@gmail.com

1. Students Research Committee, Kermanshah University of Medical Sciences, Kermanshah, Iran.

2. Faculty of health, Kermanshah University of Medical Sciences, Kermanshah, Iran.

3. Noor Research Center for Ophthalmic Epidemiology, Noor Eye Hospital, Tehran, Iran.

4. Department of Epidemiology, School of Public Health, Tehran University of Medical sciences, Tehran, Iran.

5.Department of Epidemiology, Shahid Sadoughi University of Medical Sciences, Yazd, Iran.

6.Department of General Linguistics, Allameh Tabataba'i University, Tehran, Iran.
}

and magnesium), proteins (casein and whey), and vitamins (riboflavin and Vitamin B12); thus, dairy products can have positive effects on CVD (2). On the other hand, intake of saturated fat increases low-density lipoprotein cholesterol (LDL-C), and in turn, raises the incidence of CVD, e.g. stroke and coronary heart diseases (3). Because full fat dairy products contain saturated fat, it is recommended that they be replaced by low-fat dairy; for example, margarine could be replaced by butter to decrease the intake of saturated fat $(4,5)$.

\footnotetext{
$\uparrow$ What is "already known" in this topic:

To date, no relationship has been found between consumption of various dairy products and CHD or stroke; however, it was found that only cheese decreases stroke risk by $7 \%$.

$\rightarrow$ What this article adds:

Considering the small number of studies conducted on this topic, the result of the present study is not generalizable, and more studies need to be done.
} 
Some evidence shows that low fat dairy products lower blood pressure $(6,7)$. It has been proven in some studies that Dietary Approaches to Stop Hypertension (DASH) dietary pattern, including high amount of vegetables, fruit, nuts, fish, and low fat dairy, decrease blood pressure; it can be partly put down to low fat dairy products, which play a role in cutting down on CVD (8). European handbooks also recommend DASH diet and low fat dairy products to prevent CVD; yet, it has not been fully documented with appropriate evidence (9).

Different studies have yielded different results as to the link between dairy products and stroke or CHD. Several prospective cohort studies indicated that milk, cheese, butter, and cream stand in an inverse relationship to stroke or CHD (10-12). However, some other prospective studies revealed a direct relationship between dairy products and stroke or CHD (13-15). A meta-analysis of 17 cohort studies in 2011 showed that milk consumption has an inverse relationship with overall CVD, whereas it bears no relationship to CHD and stroke (16).

As no meta-analysis was conducted to find the relationship between consumption of various dairy products and stroke and CHD and as each dairy product's mechanism acts differently in causing CVD, the need for performing a meta-analysis on this subject is highly felt to determine the effect of each dairy product one by one.

\section{Methods}

Our search was done using the strategy of combining the following keywords: ("milk" OR "cheese" OR "butter" OR "cream") AND ("cerebrovascular disease" OR "cardiovascular diseases" OR "stroke" OR "cerebral infarction" OR "coronary heart disease" OR "myocardial infarction" OR "MI" OR "ischemic heart disease" OR "IHD). The search was limited to the following databases: PubMed, April 1945 to September 2014; Science Direct, April 1823 to September 2014; and Scopus, April 1973 to September 2014. Systematic browsing studies were used to search the journal articles. The search strategy for Medline was developed first and was then adapted for the remaining databases.

\section{Inclusion criteria}

All cohort studies that examined the relationship between dairy products and stroke or CHD were included regardless of their publication date and language. Our population of interest included all individuals irrespective of their age, gender, or race. Our main focus was all dairy products and the result was incidence or mortality (stroke or CHD). Based on WHO International Classification of Diseases, ICD-10 stroke includes the following: I60-I69 (ICD)-10, and CHD is defined as acute myocardial infarction, angina pectoris, and other ischemic heart diseases (www.who.int/classifications/icd/en).

\section{Data collection and validity assessment}

Two researchers (FG and MK) independently took the responsibility of article selection to ensure that articles were selected properly, relevant to research topic, and matched the inclusion criteria. Authors' names, journals' names, and the results were available for the 2 researchers. Any disagreement between the 2 researchers was settled via consultation with a third researcher (YA).

The 2 researchers extracted the data out of the selected studies. Variables for data analysis consisted of the corresponding author's name, study title, publication date, place of the study, baseline age, population size, number of cases, follow-up period, gender, total dairy, low fat dairy, high fat dairy, the result focused (incidence or mortality of CHD or Stroke), RR $(95 \% \mathrm{CI})$ or HR $(95 \% \mathrm{CI})$ for the ratio of the highest group to the lowest group, and the variables adjusted for the analysis. In case a study was repeated more than once, the study with higher number of desired results were selected.

STROBE checklist was used to assess quality of the studies (17). Two researchers (FG \& MK) assessed the quality of the studies independently. The assessment items were as follow: (a) accurate study plan (here prospective), (b) clear and precise explanation of measurement method of dairy products, (c) precise description of measurement method of the incidence or mortality of CHD or Stroke, (d) stating the data gathering time span, (e) follow- up period, (f) referring to inclusion and exclusion criteria, and (g) explaining how loss to follow-up was addressed (Fig. 1).

\section{Measures of exposure effect and data analysis}

The general index for the assessment of the strength of RR and HR was determined with $95 \%$ confidence interval. Relative risk or hazard ratio was defined as the risk rate of

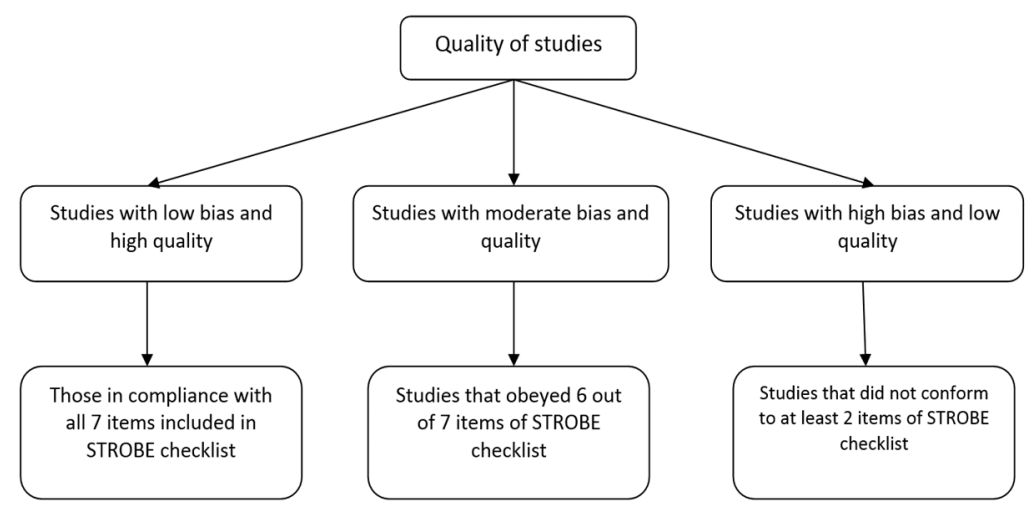

Fig. 1. Flowchart of quality of the studies 


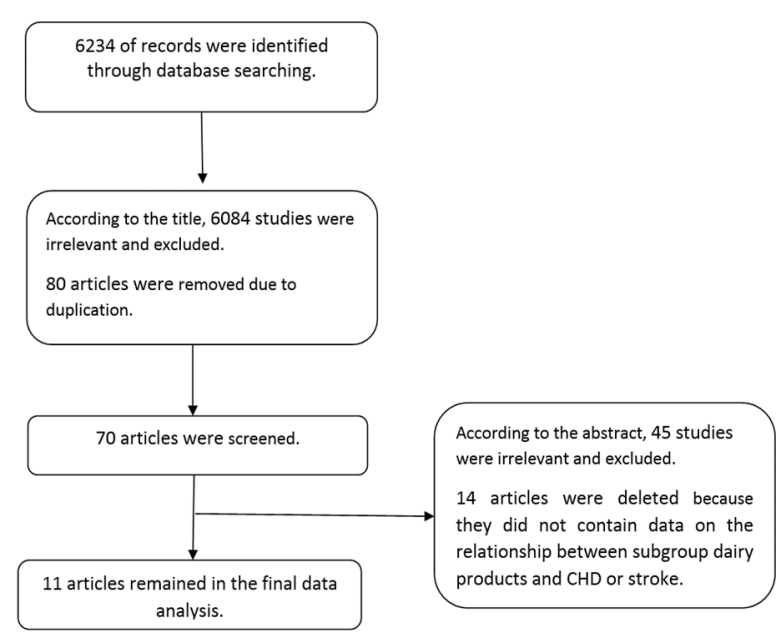

Fig. 2. Flowchart of the selection of studies for inclusion in the metaanalysis

stroke or CHD in individuals with the highest rate of consumption of dairy products in proportion to the risk rate of stroke or CHD in those with the lowest rate of consumption of dairy products. This index weight depends on the average weight of all studies based on inverse square root of studies variance. The results for males and females were reported separately. The Stata software Version 12 was used for data analysis. The data were reported via random model method. The $\mathrm{p}$ value less than 0.05 was considered significant.

Heterogeneity, publication bias, and sensitivity analysis

Heterogeneity was quantified via $\mathrm{I}^{2}$, for which Higgins classification was used, with $25 \%$ showing low heterogeneity, $50 \%$ mid heterogeneity, and $75 \%$ high heterogeneity (18). Funnel diagram was used for publication bias (19) and was statistically examined using Egger test (20). Sensitivity meta-analysis was used to exclude any study which would remarkably change the study results compared to when that study was not included (21).

\section{Results}

In the present research, 6234 studies were found in databases. After title-based assessment, 150 articles were selected and 70 were chosen after the deletion of repeated studies. After abstract examination, 25 articles with complete texts were found, and 14 studies were deleted, because they did not contain the relevant data on the relationship between dairy products and CHD and stroke. Finally, 11 studies were entered into the meta-analysis (Fig. 2).

We found 9 studies with 10 separate results in which milk was included in CHD meta-analysis of 212767 individuals with 4866 CHD cases. Ten studies were included, with 11 separate results in which milk was included in stroke meta-analysis of 440397 individuals, with 22946 stroke cases. To estimate dairy products in 10 studies, FFQ questionnaire was used, and a 7- day household inventory method was used only in 1 study (22). The follow-up period of all studies was equal to or more than 10 years. Nine studies were adapted with respect to the main variables such as age, gender, cigarette smoking, alcohol, total energy intake, and body mass index (BMI); 2 studies were not adapted to the mentioned variables $(22,23)$. Seven studies were of high quality, 2 of mid quality $(13,24)$, and 2 had low quality $(11,25)$ (Table 1).

Table 1. Characteristics of the cohort studies by subgroup dairy products consumption and CHD or stroke

\begin{tabular}{|c|c|c|c|c|c|c|c|}
\hline Author & Study, Country & $\begin{array}{c}\text { Age } \\
(\text { Years })\end{array}$ & Participants & Sex & Quality & $\begin{array}{l}\text { Follow-up } \\
\text { (Years) }\end{array}$ & $\begin{array}{l}\text { Outcome } \\
\text { (Cases) }\end{array}$ \\
\hline Praagman et al., 2014 (15) & $\begin{array}{l}\text { The Rotterdam Study, Neth- } \\
\text { erlands }\end{array}$ & $\geq 55$ & 4235 & Both & High & 17.3 & $\begin{array}{l}\text { Incidence } \\
\text { Stroke (564) } \\
\text { CHD (567) }\end{array}$ \\
\hline Dalmeijer et al., 2013 (12) & $\begin{array}{l}\text { EPIC-NL Study, Nether- } \\
\text { lands }\end{array}$ & $49-70$ & 33625 & Both & High & 13.1 & $\begin{array}{l}\text { Incidence } \\
\text { Stroke (531) } \\
\text { CHD }(1648)\end{array}$ \\
\hline Larsson et al., 2012 (27) & $\begin{array}{l}\text { The Swedish Mammography } \\
\text { Cohort and the Cohort of } \\
\text { Swedish Men }\end{array}$ & $45-83$ & 74961 & Both & High & 10.2 & $\begin{array}{l}\text { Incidence } \\
\text { Stroke (4089) }\end{array}$ \\
\hline Sonsestedt et al., 2011 (10) & $\begin{array}{l}\text { Malmo Diet and Cancer Co- } \\
\text { hort, Sweden }\end{array}$ & $44-74$ & 26445 & Both & High & 12 & $\begin{array}{l}\text { Incidence } \\
\text { Stroke (1176) } \\
\text { Coronary Event (1344) } \\
\text { CVD }(2520)\end{array}$ \\
\hline Goldbohm et al., 2011 (14) & $\begin{array}{l}\text { Netherlands Cohort Study, } \\
\text { Netherlands }\end{array}$ & $55-69$ & 58279 & Male & High & 10 & $\begin{array}{l}\text { Mortality } \\
\text { Stroke }(842) \\
\text { IHD }(2689)\end{array}$ \\
\hline $\begin{array}{l}\text { van der Pols et al., } 2009 \\
(22)\end{array}$ & $\begin{array}{l}\text { The Body Orr Cohort, Eng- } \\
\text { land and Scotland }\end{array}$ & 8 & 4374 & Both & High & 65 & $\begin{array}{l}\text { Mortality } \\
\text { CHD (378) } \\
\text { Stroke (121) }\end{array}$ \\
\hline Larsson et al., 2009 (13) & The ATBC Study, Finland & $50-69$ & 26556 & Male & Moderate & 13.6 & $\begin{array}{l}\text { Incidence } \\
\text { Stroke (3281) }\end{array}$ \\
\hline Elwood et al., 2004 (24) & $\begin{array}{l}\text { The Caerphilly Cohort } \\
\text { Study, UK }\end{array}$ & $45-59$ & 2403 & Male & Moderate & $20-24$ & $\begin{array}{l}\text { Incidence } \\
\text { Stroke (185) } \\
\text { IHD (493) } \\
\text { CVD (628) }\end{array}$ \\
\hline Sauvaget et al., 2003 (23) & $\begin{array}{l}\text { Life Span Study(LSS), Japa- } \\
\text { nese }\end{array}$ & 56 & 37130 & Both & High & 16 & $\begin{array}{l}\text { Mortality } \\
\text { Stroke (1462) }\end{array}$ \\
\hline Ness et al., 2001 (11) & $\begin{array}{l}\text { The Collaborative Study, } \\
\text { Scotland }\end{array}$ & $35-64$ & 5765 & Male & Low & 25 & $\begin{array}{l}\text { Mortality } \\
\text { Stroke (196) } \\
\text { CHD (892) } \\
\text { CVD (1212) }\end{array}$ \\
\hline Kinjo et al., 1999 (25) & Japanese & $40-69$ & 223170 & Both & Low & 15 & $\begin{array}{l}\text { Mortality } \\
\text { Stroke (11030) }\end{array}$ \\
\hline
\end{tabular}




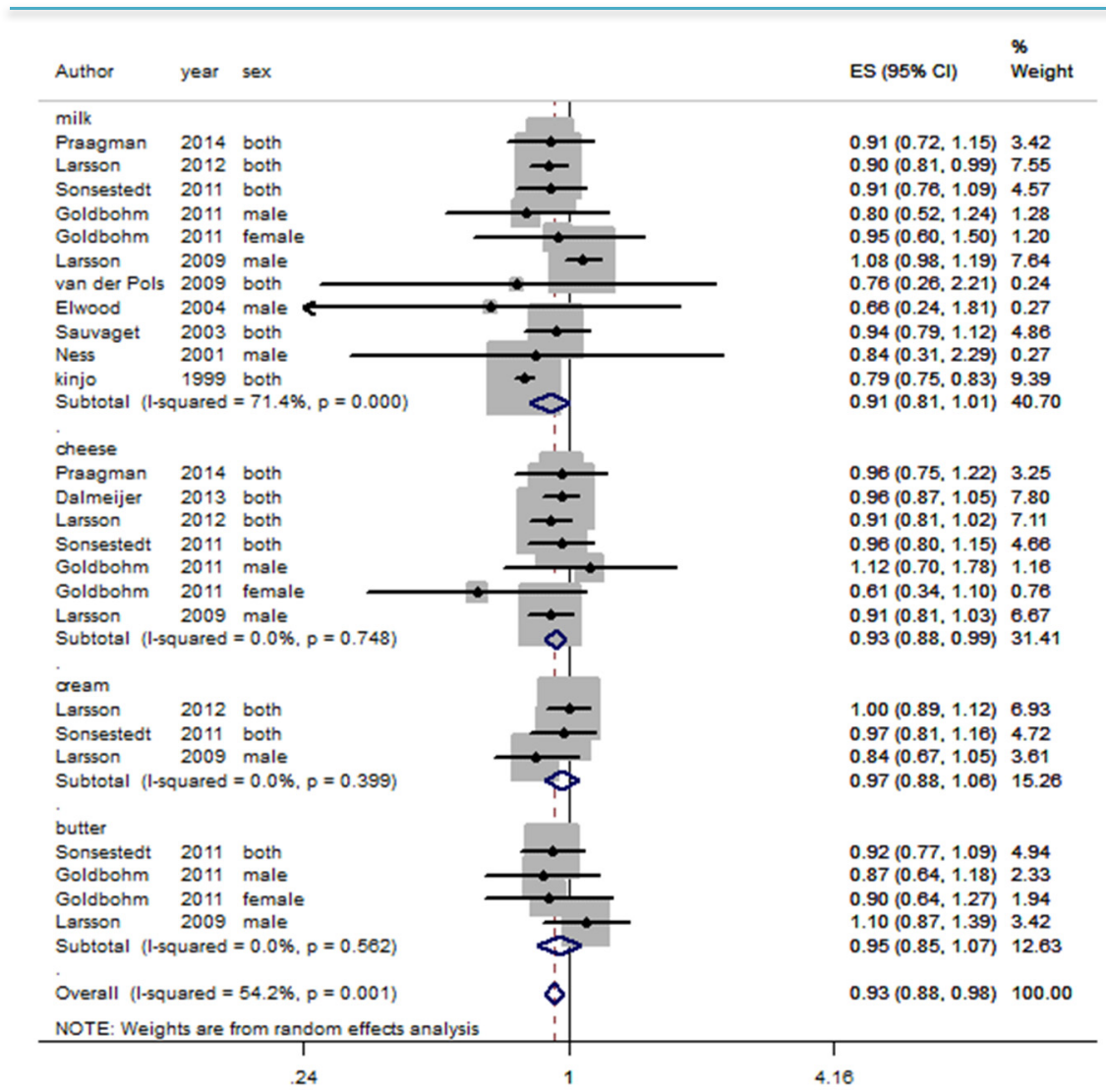

Fig. 3. Forest plot of relative risk by subgroup dairy products consumption and stroke (highest versus lowest intake)

The effect of milk, butter, cheese, and cream on stroke or CHD

Generally, there is no relationship between stroke and consumption of milk, cream, and butter: $R R=0.91(95 \%$
CI: 0.81-1.01) for milk, RR $=0.97(95 \% \mathrm{CI}: 0.88-1.06)$ for cream, and RR $=0.95$ (95\% CI: 0.85-1.07) for butter. However, it has been found that cheese decreases stroke risk: $\mathrm{RR}=0.93$ (95\% CI: 0.88-0.99) (Fig. 3).

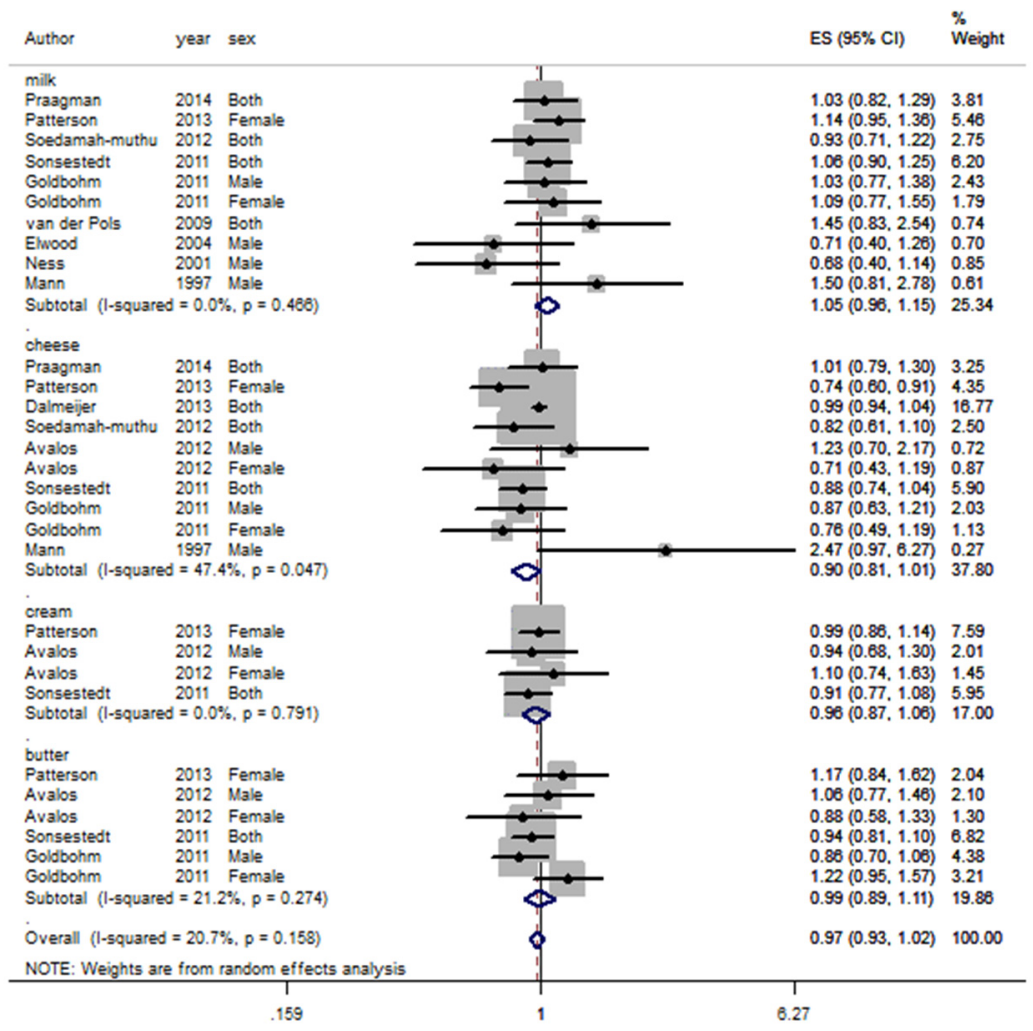

Fig. 4. Forest plot of relative risk by subgroup dairy products consumption and CHD (highest versus lowest intake) 

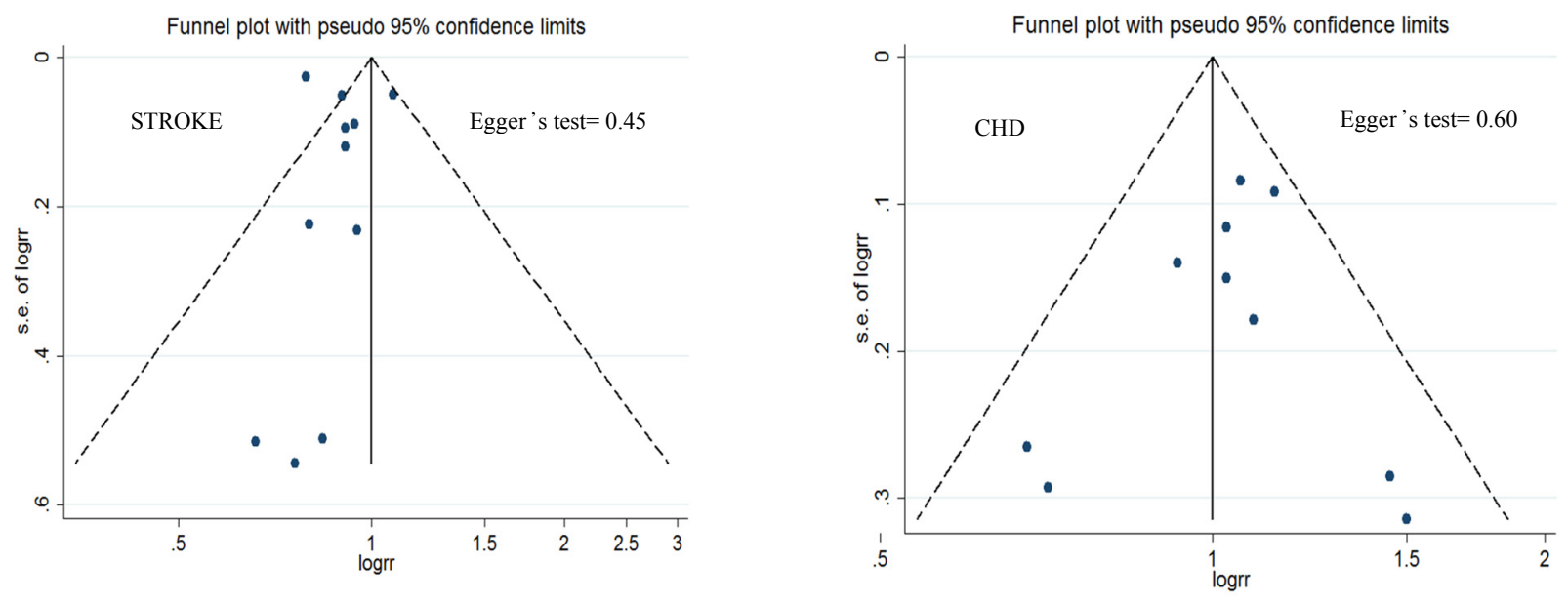

Fig. 5. Funnel plots for the analysis of milk consumption and stroke or, CHD

This meta-analysis showed different results concerning the relationship between dairy products consumption and CHD; some reported a positive effect and some negative, none of which was significant. The relationship between CHD and consumption of milk, cheese, cream, and butter is as follows, respectively: $\mathrm{RR}=1.05$ (95\% CI: 0.96-1.15), $\mathrm{RR}=0.90$ (95\%CI: 0.81-1.01), RR $=0.96$ (95\% CI: $0.87-$ $1.06), \mathrm{RR}=0.99$ (95\% CI: 0.89-1.11). In other words, there is no relationship between consumption of dairy products and CHD (Fig. 4).

Heterogeneity, meta-regression, publication bias, and sensitivity analysis

Heterogeneity was $\mathrm{I}^{2}=0 \%(\mathrm{P}=0.46)$ for milk, $\mathrm{I}^{2}=21.2 \%$ $(\mathrm{P}=0.27)$ for butter, and $\mathrm{I}^{2}=0 \%(\mathrm{p}=0.79)$ for cream, showing no heterogeneity for milk, butter, and cream in relation to CHD. However, heterogeneity did exist for cheese in relation to $\mathrm{CHD}$, ie, $\mathrm{I}^{2}=47.4 \%(\mathrm{p}=0.04)$. With regards to the heterogeneity of stroke and dairy, heterogeneity only existed for milk, $\mathrm{I}^{2}=71.4 \%(\mathrm{p}<0.001)$ and not for other products $\left(\mathrm{I}^{2}=0 \%\right)$.

It was not possible to execute a meta-regression to detect heterogeneity sources, because there were not enough studies in each subgroup.

However, considering the results of Egger test, there were not any publication bias about the relationship of subgroup dairy products and CHD. Egger test results for milk was $p=0.60$, it was $p=0.38$ for cheese, $p=0.44$ for cream, and $\mathrm{p}=0.45$ for butter, but the funnel plot was asymmetric only in the relationship between milk and CHD because of small study effects in 4 studies, which were deleted $(11,22$, $24,26)$. The study index of $\mathrm{RR}=1.06$ (95\% CI: $0.97-1.16$ ) was obtained, which did not differ remarkably from the main index for CHD (Fig. 5).

For stroke, Egger test-based publication bias results was $\mathrm{p}=0.45$ for milk, $\mathrm{p}=0.65$ for cheese, $\mathrm{p}=0.30$ for cream, and $\mathrm{p}=0.87$ for butter, so all of them were meaningless. However, the funnel plot was asymmetric only in the relationship between milk and stroke due to small study effects in 3 studies $(11,22,24)$, which were deleted, and a general estimation of the study index of RR $=0.91$ (95\% CI: 0.81 1.02) was obtained, which did not differ remarkably from the main index (Fig. 5).

The results of milk sensitivity analysis revealed that the general conclusion of the study did not differ significantly with the deletion of each study, and its index was $1.05(95 \%$ CI: $0.93-1.17)$. Moreover, the results for stroke revealed that the parameter was $0.91(0.95 \% \mathrm{CI}: 0.79-1.03)$. After excluding the ATBC study (13), the study index changed remarkably $\mathrm{RR}=0.85(95 \% \mathrm{CI}: 0.78-0.91)$, and the heterogeneity decreased from $71.4 \%$ to $12.3 \%$. The results of sensitivity analysis on the relationship between consumption of cheese, butter, and milk with CHD and stroke indicated that deletion of each study did not considerably change the main index.

\section{Discussion}

As there is a great adverse effect of CVD on public health, implementing strategies to identify changeable factors that are capable of minimizing the likelihood of these diseases is highly important. Therefore, attempting to assess the possible associations between the rate of diary intake and CHD and stroke, we used all accessible data reported by prospective cohort studies. Despite using the data of observational studies, our results indicated no significant effect of diary intake on rate of CVD.

In this meta-analysis, no relationship was found between stroke or CHD event and consumption of milk, cheese, cream and butter. Nevertheless, in 2014, the meta-analysis of 15 cohort studies showed a non-linear relationship between milk and stroke. It was found that consumption of fermented milk (200 mL/day) decreases the incidence of stroke by $18 \%$. This study expressed the relative risk of cheese consumption on stroke: [0.94(0.89-0.995)]. However, no relationship was found between the risk of stroke and consumption of non-fermented milk, cream and butter (28). Similarly, the meta-analysis done in year 2004 revealed that drinking milk has a slight effect on stroke or heart disease (29). However, in dose-response meta-analysis of prospective cohort studies, no relationship was found between milk intake and CHD or stroke (16).

Many cohort studies have conducted researches on the relationship between diary subgroups and stroke and CVD, 
among which a population-based study (2013) merits special remark; it showed that none of the dairy subgroups have any connection with CHD or stroke (12). In the Malmö Diet and Cancer Cohort, an interaction was observed between cheese and gender; and it was found that cheese consumption significantly decreases the risk of CVDs in females, but not in males (10). In addition, in Elwood prospective study on males, it was found that those with mid or high milk intake experienced stroke $=0.52$ $(0.27-0.99)$ and ischemic heart disease $=0.88(0.56-1.40)$ (30). In contrast with these findings, in the Cohort Study of Male Stroke that included males aged 50 to 69 years, it was found that drinking milk increases intracerebral hemorrhage. (Disease incidence was $41 \%$ higher in the highest quintuple compared to the lowest one: $\mathrm{RR}=1.4195 \%$ $\mathrm{CI}=1.02-1.96$.) Meanwhile, no relationship was found between consumption of cheese, butter, and dairy subtypes and stroke (13). However, it should be taken into account that the population of the mentioned study was male smokers, a group who are more exposed to the risk of CVDs; thus, the findings of that study is not generalizable.

Considering the findings, if modified or processed milk products replace milk, it will be possible to lower the incidence of CHD. This is because processed milk products decrease hypercholesterolemia. Moreover, on the ground that cholesterol and triglyceride levels are 2 main factors causing CHD, so reducing their level will decrease CHD incidence. Additionally, an expert panel concluded that whole milk may not affect blood lipids as predicted from its fat content and fat composition (31). In Rossouw's study it was found that intake of skim milk and yoghurt lowers cholesterol level, but consuming milk has no effect on plasma cholesterol (32), and that fermented-milk consumers are $15 \%$ less prone to CVDs (10). In addition, a double blind crossover study indicated that daily intake of 90 gr immune milk decreases total cholesterol by $5.2 \%(95 \% \mathrm{CI}=2.5-7 / 9)$ and $\mathrm{LDL}$ by $7.4 \%(95 \% \mathrm{CI}=4.1-10.7)$; this study claimed that immune milk can be efficient in nutritional management of those with hypercholesterolemia (33).

Limitations of this study were as follow: (1) Although the relative risk obtained in this study was adjusted for many important variables, some unadjusted variables may still be present and residual confounding may also exist; (2) While cohort studies are firm in causality, nutritional habits may change in the course of time, and therefore, the observed connection cannot be authentically approved.

\section{Conclusions}

No relationship was found between various dairy products and CHD or stroke; only cheese decreased stroke risk by $7 \%$. Moreover, considering the fewness of the studies, the results are not generalizable, and more studies need to be conducted.

\section{Acknowledgements}

We would like to thank all those researchers who helped us to conduct this study.

\section{Funding}

This work was supported by Kermanshah University of
Medical Sciences grants/

\section{Conflict of Interests: None.}

\section{References}

1. Organization WH. Cardiovascular diseases: Fact sheet No. 317. September 2012. Available on line at: http://www.who.int/mediacentre/factsheets/fs317/en/index html Last retrieved September 4th. 2012.

2. Jakobsen MU, O'Reilly EJ, Heitmann BL, Pereira MA, Bälter K, Fraser $\mathrm{GE}$, et al. Major types of dietary fat and risk of coronary heart disease: a pooled analysis of 11 cohort studies. Am J Clin Nutr. 2009;89(5):1425-32.

3. Sacks FM, Katan M. Randomized clinical trials on the effects of dietary fat and carbohydrate on plasma lipoproteins and cardiovascular disease. Am J Med. 2002;113(9):13-24.

4. Smith A, Schmerlaib Y, Kellett E. The Australian guide to healthy eating: background information for nutrition educators: Commonwealth Department of Health and Family Services; 1998.

5. Becker W, Lyhne N, Pedersen AN, Aro A, Fogelholm M, Phorsdottir I, et al. Nordic Nutrition Recommendations 2004-integrating nutrition and physical activity. Scandinavian J Nutr. 2004;48(4):178-87.

6. Toledo E, Delgado-Rodríguez M, Estruch R, Salas-Salvadó J, Corella D, Gomez-Gracia E, et al. Low-fat dairy products and blood pressure: follow-up of 2290 older persons at high cardiovascular risk participating in the PREDIMED study. Br J Nutr. 2009;101(01):59-67.

7. Wang L, Manson JE, Buring JE, Lee I-M, Sesso HD. Dietary intake of dairy products, calcium, and vitamin $\mathrm{D}$ and the risk of hypertension in middle-aged and older women. Hypertension. 2008;51(4):1073-9.

8. Appel LJ, Moore TJ, Obarzanek E, Vollmer WM, Svetkey LP, Sacks FM, et al. A clinical trial of the effects of dietary patterns on blood pressure. N Engl J Med. 1997;336(16):1117-24.

9. Graham I, Atar D, Borch-Johnsen K, Boysen G, Burell G, Cifkova R, et al. European guidelines on cardiovascular disease prevention in clinical practice: executive summary. Eur Heart J. 2007;28(19):2375-414.

10. Sonestedt E, Wirfält E, Wallström P, Gullberg B, Orho-Melander M, Hedblad B. Dairy products and its association with incidence of cardiovascular disease: the Malmö diet and cancer cohort. Eur J Epidemiol. 2011;26(8):609-18.

11. Ness A, Smith GD, Hart C. Milk, coronary heart disease and mortality. J Epid Commun Health. 2001;55(6):379-82.

12. Dalmeijer GW, Struijk EA, van der Schouw YT, Soedamah-Muthu SS, Verschuren WM, Boer JM, et al. Dairy intake and coronary heart disease or stroke - a population-based cohort study. Int J Cardiol. 2013;167(3):925-9.

13. Larsson SC, Männistö S, Virtanen MJ, Kontto J, Albanes D, Virtamo J. Dairy foods and risk of stroke. Epidemiology (Cambridge, Mass). 2009;20(3):355.

14. Goldbohm RA, Chorus AM, Garre FG, Schouten LJ, van den Brandt PA. Dairy consumption and 10-y total and cardiovascular mortality: a prospective cohort study in the Netherlands. Am J Clin Nutr. 2011:ajcn. 000430.

15. Praagman J, Franco OH, Ikram MA, Soedamah-Muthu SS, Engberink MF, van Rooij FJ, et al. Dairy products and the risk of stroke and coronary heart disease: the Rotterdam Study. Eur J Nutr. 2014:1-10.

16. Soedamah-Muthu SS, Ding EL, Al-Delaimy WK, Hu FB, Engberink MF, Willett WC, et al. Milk and dairy consumption and incidence of cardiovascular diseases and all-cause mortality: dose-response metaanalysis of prospective cohort studies. Am J Clin Nutr 2011;93(1):158-71.

17. Von Elm E, Altman DG, Egger M, Pocock SJ, Gøtzsche PC, Vandenbroucke JP, et al. The Strengthening the Reporting of Observational Studies in Epidemiology (STROBE) statement: guidelines for reporting observational studies. Prevent Med. 2007;45(4):247-51.

18. Huedo-Medina TB, Sánchez-Meca J, Marín-Martínez F, Botella J. Assessing heterogeneity in meta-analysis: Q statistic or $\mathrm{I}^{2}$ index? Psychol Method. 2006;11(2):193.

19. Higgins JP, Green S. Cochrane handbook for systematic reviews of interventions: Wiley Online Library; 2008.

20. Egger M, Smith GD, Schneider M, Minder C. Bias in meta-analysis detected by a simple, graphical test. Br Med J. 1997;315(7109):62934.

21. Tobias A. Assessing the influence of a single study in the meta-anyalysis estimate. Stata Tech Bull. 1999;8(47).

22. Van der Pols J, Gunnell D, Williams G, Holly J, Bain C, Martin R. 
Childhood dairy and calcium intake and cardiovascular mortality in adulthood: 65-year follow-up of the Boyd Orr cohort. Heart. 2009;95(19):1600-6.

23. Sauvaget C, Nagano J, Allen N, Grant EJ, Beral V. Intake of animal products and stroke mortality in the Hiroshima/Nagasaki Life Span Study. Int J Epidemiol. 2003;32(4):536-43.

24. Elwood PC, Pickering JE, Fehily A, Hughes J, Ness A. Milk drinking, ischaemic heart disease and ischaemic stroke I. Evidence from the Caerphilly cohort. Eur J Clin Nutr. 2004;58(5):711-7.

25. Kinjo Y, Beral V, Akiba S, Key T, Mizuno S, Appleby P, et al. Possible protective effect of milk, meat and fish for cerebrovascular disease mortality in Japan. J Epidemiol. 1999;9(4):268-74.

26. Mann JI, Appleby PN, Key TJ, Thorogood M. Dietary determinants of ischaemic heart disease in health conscious individuals. Heart. 1997;78(5):450-5.

27. Larsson SC, Virtamo J, Wolk A. Dairy consumption and risk of stroke in Swedish women and men. Stroke. 2012;43(7):1775-80.

28. Hu D, Huang J, Wang Y, Zhang D, Qu Y. Dairy foods and risk of stroke: a meta-analysis of prospective cohort studies. Nutrition, Metabolism and Cardiovascular Diseases. 2014;24(5):460-9.

29. Elwood PC, Pickering JE, Hughes J, Fehily A, Ness A. Milk drinking, ischaemic heart disease and ischaemic stroke II. Evidence from cohort studies. Eur J Clin Nutr. 2004;58(5):718-24.

30. Elwood PC, Strain J, Robson PJ, Fehily AM, Hughes J, Pickering J, et al. Milk consumption, stroke, and heart attack risk: evidence from the Caerphilly cohort of older men. J Epid Commun Health. 2005;59(6):502-5.

31. Berner LA. Roundtable discussion on milkfat, dairy foods, and coronary heart disease risk. The Journal of nutrition. 1993;123(6):1175-84.

32. Rossouw J, Burger E, Van der Vyver P, Ferreira J. The effect of skim milk, yoghurt, and full cream milk on human serum lipids. Am J Clin Nutr. 1981;34(3):351-6.

33. Sharpe SJ, Gamble GD, Sharpe DN. Cholesterol-lowering and blood pressure effects of immune milk. Am J Clin Nutr. 1994;59(4):929-34. 